\title{
Minimally invasive esophagectomy: Direction of the art
}

Shawn S. Groth, MD, MS, and Bryan M. Burt, MD

\section{BACKGROUND: VALUE OF MINIMALLY INVASIVE THORACIC SURGERY}

Thoracoscopic lobectomy is an archetypal model of how careful adoption of minimally invasive surgery offers value in health care. Thoracoscopy improves the quality of lobectomy compared with thoracotomy by reducing pain, improving quality of life (QOL), increasing the probability of completing adjuvant therapy, and potentially even benefiting long-term survival. ${ }^{1}$ Thoracoscopic lobectomy consequently reduces health care costs by decreasing length of stay, reducing complications, and facilitating speedier return to normal activities. ${ }^{2,3}$ Available and emerging evidence supports a similar direction for minimally invasive esophagectomy (MIE).

\section{ADOPTION OF MIE}

Led largely by Luketich and colleagues, the turn of the century established the safety and feasibility of total laparoscopic/thoracoscopic $\mathrm{MIE}^{4}$ (referred to hereafter as conventional MIE) and its technical components including pyloroplasty, ${ }^{5}$ omental flap harvest and anastomotic buttress, ${ }^{6}$ and thoracoscopic intrathoracic anastomosis. ${ }^{7}$ Observational studies have since demonstrated no difference in oncologic outcomes between conventional MIE and open esophagectomy, and these metrics include extent of lymphadenectomy, margin status, and survival. ${ }^{8} \mathrm{QOL}$ is an essential outcome measure of therapeutic intervention in cancer patients, and MIE has been shown to have improved postoperative QOL relative to open esophagectomy. ${ }^{9}$ Corresponding to the emergence of these data, routine use of MIE has increased globally over the past decade. As an example, among 6022 esophagectomies performed during the period of 2015 to 2018 in 39 centers around the world, the majority of esophagectomies (53\%) were performed using minimally invasive approaches. ${ }^{10}$

\footnotetext{
From the Division of Thoracic Surgery, Michael E. DeBakey Department of Surgery, Baylor College of Medicine, Houston, Tex.

Received for publication July 1, 2020; revisions received Jan 5, 2021; accepted for publication Jan 8, 2021; available ahead of print Jan 21, 2021.

Address for reprints: Shawn S. Groth, MD, MS, FACS, Division of Thoracic Surgery, Michael E. DeBakey Department of Surgery, One Baylor Plaza, BCM 390, Houston, TX 77030 (E-mail: Shawn.Groth@bcm.edu).

J Thorac Cardiovasc Surg 2021;162:701-4

$0022-5223 / \$ 36.00$

Copyright (C) 2021 by The American Association for Thoracic Surgery

https://doi.org/10.1016/j.jtcvs.2021.01.031
}

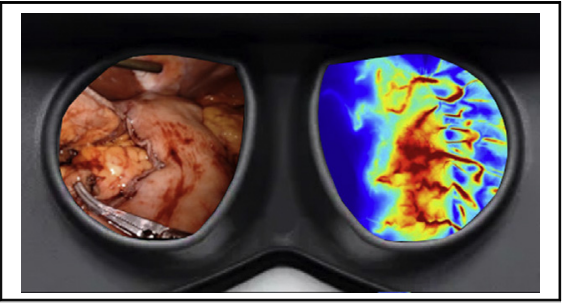

Viewfinder image of RAMIE showing the gastric conduit and its perfusion by fluorescence.

$$
\begin{aligned}
& \text { CENTRAL MESSAgE } \\
& \text { The direction of minimally inva- } \\
& \text { sive esophagectomy is sup- } \\
& \text { ported by data, enabled by } \\
& \text { surgical and technological inno- } \\
& \text { vation, controlled by provider } \\
& \text { equipoise, and positioned in our } \\
& \text { standard of care. }
\end{aligned}
$$

See Commentaries on pages 705, 707, and 708

\section{LEVEL I EVIDENCE COMPARING MIE AND OPEN ESOPHAGECTOMY}

Two multicenter randomized trials comparing open esophagectomy with MIE have been published over the last 8 years and were reviewed recently in the Journal. ${ }^{11}$ The TIME (Traditional Invasive vs Minimally Invasive Esophagectomy) trial was reported in The Lancet in 2012 and compared conventional MIE with open, modified McKeown esophagectomy. ${ }^{12}$ The MIRO (Oesphagectomie Pour Cancer par Voie Conventionnelle ou Coelio-Assisté) trial was published in the New England Journal of Medicine in 2019 and compared Ivor Lewis esophagectomy performed by a hybrid laparoscopic/thoracotomy approach with one performed fully open, by laparotomy and thoracotomy. ${ }^{13}$ There was no difference in length of stay or 30- and 90-mortality between open esophagectomy and MIE in either trial. Each demonstrated significantly lower rates of pneumonia following MIE, although this difference in the MIRO trial was supported by a relatively high rate of pneumonia in the open group $(34 \%))^{12,13}$ There were no differences in extent of lymphadenectomy, rates of R0 resection, or disease-free survival at 3 years $^{13,14}$ (Table 1). Importantly, QOL was improved in the MIE cohorts in both trials, 
TABLE 1. Comparison of perioperative and pathologic outcomes of open, hybrid, and conventional MIE

\begin{tabular}{llllllll}
\hline \multicolumn{1}{c}{ Approach } & Trial & N & Pneumonia & Leak & 30-d mortality & R0 rate & LN count \\
\hline Open & TIME & 56 & $34 \% *$ & $7 \%$ & $0 \%$ & $84 \%$ & $21(4-47)$ \\
Conventional MIE & TIME & 59 & $12 \% *$ & $12 \%$ & $2 \%$ & $92 \%$ & $20(3-44)$ \\
Open & MIRO & 104 & $16.5 \% \dagger$ & $7 \%$ & $1 \%$ & $98.1 \%$ & $22(9-64)$ \\
Hybrid MIE & MIRO & 103 & $12.8 \% \dagger$ & $11 \%$ & $1 \%$ & $95.1 \%$ & $21(7-76)$ \\
\hline
\end{tabular}

LN, Lymph node; TIME, Traditional Invasive Versus Minimally Invasive Esophagectomy; MIRO, Oesphagectomie Pour Cancer par Voie conventionnelle ou Coelio-Assistée; $M I E$, minimally invasive esophagectomy. *In-hospital pneumonia rate. $\dagger 30$-day pneumonia rate.

at 1 and 2 years following surgery. ${ }^{15,16}$ The MIRO trial has taught us that approaching the abdomen laparoscopically is a major contributor to the short-term advantages of MIE. Eliminating thoracotomy is rationally expected to further enhance its benefits. Although not yet supported by level 1 evidence, observational studies have compared conventional and hybrid MIE and demonstrated reduced postoperative pain, decreased rates of pneumonia, and even improved overall survival in the conventional (totally minimally invasive) approach. ${ }^{17,18}$

\section{LEVEL I EVIDENCE COMPARING ROBOTIC AND OPEN ESOPHAGECTOMY}

Advanced digital optics and high precision in the control of robotic surgical instrumentation have supported the rising popularity and adoption of robot-assisted minimally invasive esophagectomy (RAMIE). A variety of reports have now demonstrated safety and feasibility in RAMIE for patients with esophageal cancer, ${ }^{19,20}$ and level I evidence is emerging. ROBOT (Robot-Assisted Minimally Invasive Thoraco-Laparoscopic Esophagectomy Versus Open Transthoracic Esophagectomy for Resectable Esophageal Cancer) was a single-center, randomized trial that compared outcomes of open esophagectomy $(\mathrm{n}=55)$ with RAMIE $(\mathrm{n}=54)$ via a modified McKeown approach. In this trial, RAMIE was associated with a $26 \%$ relative risk reduction in overall postoperative complications and similar oncologic outcomes compared with open esophagectomy. There was no difference between the open and robotic groups in outcomes, including $\mathrm{R} 0$ resection, extent of lymphadenectomy, and 30-day and 90-day mortality. In line with randomized data for conventional and hybrid MIE, patients undergoing RAMIE had improved functional recovery at 14 days and better QOL at 6 weeks. ${ }^{21}$ Similar to trends seen in the TIME trial, the open group in the ROBOT trial had greater than expected rates of complications for patients undergoing open esophagectomy $(80 \%)$ which accentuated its advantage over the RAMIE group (59\%).

\section{CONVENTIONAL MIE VERSUS RAMIE}

Retrospective observational data have supported comparable outcomes for RAMIE and conventional MIE across domains of operative morbidity, oncologic outcomes, and survival. ${ }^{22,23}$ Level 1 evidence is not yet available; however,
RAMIE and conventional MIE are being compared prospectively for patients with adenocarcinoma of the distal esophagus, in the ROBOT-2 trial (NCT04306458). It is clear, however, that the capital and maintenance costs of the robotic system required for RAMIE are greater than the platforms required for conventional and open MIE. We are not aware of a rigorous comparison of economic considerations between conventional MIE, RAMIE, and open esophagectomy but anticipate publications comparing relevant cost matrices over the next 1 to 2 years. Given that 90 -day hospital costs of esophagectomy are increased $40 \%$ by complications, ${ }^{24}$ it is feasible to hypothesize that the lower rates of complications from MIE demonstrated in TIME, MIRO, and ROBOT could mitigate, to some extent, the costs of MIE.

\section{VOLUME-OUTCOME CONSIDERATIONS FOR ESOPHAGECTOMY}

The relationship of institutional volume and outcomes following esophagectomy remains controversial, although standards have been recommended by organizations vested in surgical quality (eg, minimum of 20 esophagectomies a year). ${ }^{25}$ Surprisingly, only $42 \%$ of institutions participating in the Society of Thoracic Surgeons (STS) General Thoracic Database, performed at least 5 esophagectomies a year, ${ }^{26}$ and analyses of the STS and National Cancer Database have not demonstrated a clear volume-outcome relationship for esophagectomy with the exception that very low-volume centers (median 1.3 cases per year; [interquartile range, 0.7-1.7]) have had worse outcomes in National Cancer Database studies. ${ }^{26-28}$

\section{LEARNING MIE}

Whereas institutional volume considerations alone should not limit the transition to MIE by thoracic surgeons, conventional MIE and RAMIE are highly complex, nuanced operations that should be approached responsibly. The learning curve for conventional MIE has been studied using a variety of metrics such as operative time, intraoperative blood loss, number of resected lymph nodes, and morbidity, and the balance of literature would suggest that proficiency occurs around 35-40 cases. ${ }^{29,30}$ A multicenter retrospective study of 646 patients investigated the effect of the learning curve for conventional Ivor Lewis MIE using 
a primary outcome of anastomotic leak. This study demonstrated that an average of 119 cases were required to achieve a plateau in the rate of anastomotic leak of about $8 \%$, from a starting rate of $18.8 \% .^{31}$ Learning curve analyses performed for RAMIE have suggested that proficiency is achieved at $40-70$ cases. ${ }^{32,33}$ Supported by the proven benefit of hybrid laparoscopic/thoracotomy MIE in the MIRO trial, surgeons have reasonably approached their transition to MIE in a stepwise fashion using a hybrid intermediate such as laparoscopy/thoracotomy or laparotomy/ thoracoscopy. Universal to the discussion section of all learning curve manuscripts and highlighted frequently by leaders in the field of MIE, however, is the importance of structured training and proctorship for those learning these operations.

\section{THE MINIMALLY INVASIVE INTRATHORACIC ANASTOMOSIS}

One of most technically challenging aspects of MIE is construction of an intrathoracic anastomosis and anastomotic leak is one of the greatest sources of morbidity following esophagectomy. Among MIE and open esophagectomy cases within the STS database, the frequency of anastomotic leak was not statistically different overall. However, a statistically greater number of leaks managed nonoperatively were reported in patients undergoing Ivor Lewis MIE (8.3\%) compared with Ivor Lewis open esophagectomy $(4.3 \%) .{ }^{34}$ A variety of techniques for fashioning the thoracoscopic anastomosis are used in the practice of conventional MIE and RAMIE that include the stapled EEA anastomosis with thoracoscopic ${ }^{35}$ or transoral anvil placement,${ }^{36}$ the modified Collard stapled technique, ${ }^{37,38}$ and the total thoracoscopic "handsewn" technique. ${ }^{39}$ We are not aware of any study rigorously comparing anastomotic outcomes among techniques and submit that the technical advantages of robotics should renew the opportunity to compare the benefits and limitations of stapled and sewn techniques.

\section{CONCLUSIONS: DIRECTION OF THE ART}

MIE can be considered within the standard of care for patients with esophageal cancer. The direction of MIE is driven by surgical and technological innovation and responsibly regulated by its surgeons. Robotics is firmly integrated in thoracic surgery and RAMIE is a natural progression to MIE for robotic thoracic surgeons. Evidence for the comparative efficacy of RAMIE and conventional MIE is accruing and metrics including extent of nodal dissection, efficacy, morbidity, QOL, and cost-effectiveness are being prospectively evaluated in the ROBOT-2 trial (NCT04306458). We anticipate steady forward advancement in the art and science of MIE that will likely bring an increase in total minimally invasive approaches including RAMIE, and development of clinically relevant applications of fluorescence imaging in evaluating conduit perfusion $^{40,41}$ and mapping regional or sentinel lymph nodes. ${ }^{42}$ The direction of MIE is forward, stimulating, and brisk.

\section{Conflict of Interest Statement}

Dr Groth reported Intuitive Surgical Inc (speaker and proctor honoraria); Dr Burt reported Intuitive Surgical Inc (proctor honoraria).

The Journal policy requires editors and reviewers to disclose conflicts of interest and to decline handling or reviewing manuscripts for which they may have a conflict of interest. The editors and reviewers of this article have no conflicts of interest.

\section{References}

1. Klapper J, D'Amico TA. VATS versus open surgery for lung cancer resection: moving toward a minimally invasive approach. J Natl Compr Canc Netw. 2015;13:162-4.

2. Geller AD, Zheng H, Mathisen DJ, Wright CD, Lanuti M. Relative incremental costs of complications of lobectomy for stage I non-small cell lung cancer. $J$ Thorac Cardiovasc Surg. 2018;155:1804-11

3. Burt BM, Kosinski AS, Shrager JB, Onaitis MW, Weigel T. Thoracoscopic lobectomy is associated with acceptable morbidity and mortality in patients with predicted postoperative forced expiratory volume in 1 second or diffusing capacity for carbon monoxide less than 40\% of normal. J Thorac Cardiovasc Surg. 2014 148:19-28; discussion 28-29.e11.

4. Fernando HC, Christie NA, Luketich JD. Thoracoscopic and laparoscopic esophagectomy. Semin Thorac Cardiovasc Surg. 2000;12:195-200.

5. Murphy TJ, Levy RM, Crist LR, Luketich JD. Minimally invasive pyloroplasty. Semin Thorac Cardiovasc Surg. 2010;22:338-40.

6. Lu M, Luketich JD, Levy RM, Awais O, Sarkaria I, Visintainer P, et al. Anastomotic complications after esophagectomy: influence of omentoplasty in propensity-weighted cohorts. J Thorac Cardiovasc Surg. 2020;159:2096-105.

7. Levy RM, Luketich JD. Minimally invasive intrathoracic esophagogastric anastomosis. Semin Thorac Cardiovasc Surg. 2010;22:256-8.

8. Mitzman B, Lutfi W, Wang CH, Krantz S, Howington JA, Kim KW. Minimally invasive esophagectomy provides equivalent survival to open esophagectomy: an analysis of the National Cancer Database. Semin Thorac Cardiovasc Surg. 2017; 29:244-53.

9. Taioli E, Schwartz RM, Lieberman-Cribbin W, Moskowitz G, van Gerwen M, Flores R. Quality of life after open or minimally invasive esophagectomy in patients with esophageal cancer-a systematic review. Semin Thorac Cardiovasc Surg. 2017;29:377-90

10. Kuppusamy MK, Low DE, International Esodata Study Group (IESG). Evaluation of international contemporary operative outcomes and management trends associated with esophagectomy: a 4-year study of $>6000$ patients using ECCG definitions and the online Esodata database. Ann Surg. October 14, 2020 [Epub ahead of print].

11. Hofstetter WL. Open versus hybrid minimally invasive esophagectomy: join the crowd, but do not throw away your abdominal retractors just yet. J Thorac Cardiovasc Surg. 2019;158:1475-8.

12. Biere SS, van Berge Henegouwen MI, Maas KW, Bonavina L, Rosman C, Garcia JR, et al. Minimally invasive versus open oesophagectomy for patients with oesophageal cancer: a multicentre, open-label, randomised controlled trial Lancet. 2012;379:1887-92.

13. Mariette C, Markar SR, Dabakuyo-Yonli TS, Meunier B, Pezet D, Collet D, et al Hybrid minimally invasive esophagectomy for esophageal cancer. N Engl J Med. 2019;380:152-62.

14. Straatman J, van der Wielen N, Cuesta MA, Daams F, Roig Garcia J, et al. Minimally invasive versus open esophageal resection: three-year follow-up of the previously reported randomized controlled trial: the TIME trial. Ann Surg. 2017 266:232-6. 
15. Maas KW, Cuesta MA, van Berge Henegouwen MI, Roig J, Bonavina L, Rosman C, et al. Quality of life and late complications after minimally invasive compared to open esophagectomy: results of a randomized trial. World J Surg. 2015;39:1986-93.

16. Mariette C, Markar S, Dabakuyo-Yonli TS, Meunier B, Pezet D, Collet D, et al. Health-related quality of life following hybrid minimally invasive versus open esophagectomy for patients with esophageal cancer, analysis of a multicenter, open-label, randomized phase III controlled trial: the MIRO trial. Ann Surg. 2020;271:1023-9.

17. Berlth F, Plum PS, Chon SH, Gutschow CA, Bollschweiler E, Holscher AH. Total minimally invasive esophagectomy for esophageal adenocarcinoma reduces postoperative pain and pneumonia compared to hybrid esophagectomy. Surg Endosc. 2018;32:4957-65.

18. Burdall OC, Boddy AP, Fullick J, Blazeby J, Krysztopik R, Streets C, et al. A comparative study of survival after minimally invasive and open oesophagectomy. Surg Endosc. 2015;29:431-7.

19. Cerfolio RJ, Bryant AS, Hawn MT. Technical aspects and early results of robotic esophagectomy with chest anastomosis. J Thorac Cardiovasc Surg. 2013;145: 90-6.

20. Kim DJ, Hyung WJ, Lee CY, Lee JG, Haam SJ, Park IK, et al. Thoracoscopic esophagectomy for esophageal cancer: feasibility and safety of robotic assistance in the prone position. J Thorac Cardiovasc Surg. 2010;139:53-9.e51.

21. van der Sluis PC, van der Horst S, May AM, Schippers C, Brosens LAA, Joore HCA, et al. Robot-assisted minimally invasive thoracolaparoscopic esophagectomy versus open transthoracic esophagectomy for resectable esophageal cancer: a randomized controlled trial. Ann Surg. 2019;269:621-30.

22. Espinoza-Mercado F, Imai TA, Borgella JD, Sarkissian A, Serna-Gallegos D, Alban RF, et al. Does the approach matter? Comparing survival in robotic, minimally invasive, and open esophagectomies. Ann Thorac Surg. 2019;107:378-85.

23. Tagkalos E, Goense L, Hoppe-Lotichius M, Ruurda JP, Babic B, Hadzijusufovic E, et al. Robot-assisted minimally invasive esophagectomy (RAMIE) compared to conventional minimally invasive esophagectomy (MIE) for esophageal cancer: a propensity-matched analysis. Dis Esophagus. 2020; 33:doz060.

24. Geller AD, Zheng H, Gaissert H, Mathisen D, Muniappan A, Wright C, et al. Relative incremental cost of postoperative complications of esophagectomy. Semin Thorac Cardiovasc Surg. 2019;31:290-9.

25. The Leapfrog Group. Complex Adult Surgery; 2019. Washington, DC: The Leapfrog Group; 2019. Available at: https://ratings.leapfroggroup.org/measure/ hospital/complex-adult-surgery. Accessed February 14, 2021.

26. Society of Thoracic Surgeons General Thoracic Surgery Database Task Force. The Society of Thoracic Surgeons composite score for evaluating esophagectomy for esophageal cancer. Ann Thorac Surg. 2017;103:1661-7.

27. Wright CD, Kucharczuk JC, O'Brien SM, Grab JD, Allen MS. Society of Thoracic Surgeons General Thoracic Surgery database. Predictors of major morbidity and mortality after esophagectomy for esophageal cancer: a Society of Thoracic Surgeons General Thoracic Surgery database risk adjustment model. J Thorac Cardiovasc Surg. 2009; 137:587-95; discussion 596.

28. Jacobs RC, Groth S, Farjah F, Wilson MA, Petersen LA, Massarweh NN. Potential impact of "Take the Volume Pledge" on access and outcomes for gastrointestinal cancer surgery. Ann Surg. 2019;270:1079-89.
29. Tapias LF, Morse CR. Minimally invasive Ivor Lewis esophagectomy: description of a learning curve. J Am Coll Surg. 2014;218:1130-40.

30. White A, Kucukak S, Lee DN, Mazzola E, Zhang Y, Swanson SJ. Ivor Lewis minimally invasive esophagectomy for esophageal cancer: an excellent operation that improves with experience. J Thorac Cardiovasc Surg. 2019;157: 783-9.

31. van Workum F, Stenstra M, Berkelmans GHK, Slaman AE, van Berge Henegouwen MI, Gisbertz SS, et al. Learning curve and associated morbidity of minimally invasive esophagectomy: a retrospective multicenter study. Ann Surg. 2019;269:88-94.

32. Sarkaria IS, Rizk NP, Grosser R, Goldman D, Finley DJ, Ghanie A, et al. Attaining proficiency in robotic-assisted minimally invasive esophagectomy while maximizing safety during procedure development. Innovations (Phila). 2016; 11:268-73

33. van der Sluis PC, Ruurda JP, van der Horst S, Goense L, van Hillegersberg R. Learning curve for robot-assisted minimally invasive thoracoscopic esophagectomy: results from 312 cases. Ann Thorac Surg. 2018;106:264-71.

34. Sihag S, Kosinski AS, Gaissert HA, Wright CD, Schipper PH. Minimally invasive versus open esophagectomy for esophageal cancer: a comparison of early surgical outcomes from the Society of Thoracic Surgeons National Database. Ann Thorac Surg. 2016;101:1281-8; discussion 1288-9.

35. Okusanya OT, Sarkaria IS, Hess NR, Nason KS, Sanchez MV, Levy RM, et al. Robotic assisted minimally invasive esophagectomy (RAMIE): the University of Pittsburgh Medical Center initial experience. Ann Cardiothorac Surg. 2017 6:179-85.

36. Meredith K, Huston J, Andacoglu O, Shridhar R. Safety and feasibility of robotic-assisted Ivor-Lewis esophagectomy. Dis Esophagus. 2018;31(7) https://doi.org/10.1093/dote/doy005.

37. Kesler KA, Ramchandani NK, Jalal SI, Stokes SM, Mankins MR, Ceppa D, et al. Outcomes of a novel intrathoracic esophagogastric anastomotic technique. $J$ Thorac Cardiovasc Surg. 2018;156:1739-45.e1731.

38. Hagen JA. A novel intrathoracic esophagogastric anastomotic technique: potential benefit for patients undergoing a robotic-assisted minimally invasive esophagectomy. J Thorac Cardiovasc Surg. 2018;156:1746-7.

39. Cerfolio RJ, Wei B, Hawn MT, Minnich DJ. Robotic esophagectomy for cancer: early results and lessons learned. Semin Thorac Cardiovasc Surg. 2016;28:160-9.

40. Okusanya O, Lu M, Luketich JD, Sarkaria IS. Intraoperative near infrared fluorescence imaging for the assessment of the gastric conduit. J Thorac Dis. 2019; 11:S750-4.

41. Van Daele E, Van Nieuwenhove Y, Ceelen W, Vanhove C, Braeckman BP, Hoorens A, et al. Near-infrared fluorescence guided esophageal reconstructive surgery: a systematic review. World J Gastrointest Oncol. 2019;11:250-63.

42. Hachey KJ, Gilmore DM, Armstrong KW, Harris SE, Hornick JL, Colson YL, et al. Safety and feasibility of near-infrared image-guided lymphatic mapping of regional lymph nodes in esophageal cancer. J Thorac Cardiovasc Surg. 2016;152:546-54.

Key Words: esophagectomy, minimally invasive, open, robotic, MIE, RAMIE, clinical trial, evidence 